\title{
Comparison of two different ways to apply a circular plaster cast for distal radius fractures: biomechanical study
}

\author{
Alejandro Espejo-Reina ${ }^{1,2}$, María T. Carrascal-Morillo ${ }^{3}$ and Alberto D. Delgado-Martínez ${ }^{4,5^{*}}$ (D)
}

\begin{abstract}
Introduction: Although conservative treatment with circular plaster cast is the most commonly used method in distal radius fractures, the best method to apply it remains unclear.

Material and methods: Two frequently used configurations of circular plaster cast (with and without a splint) were selected to compare. Group C was applied only with circular bandages (three units) and group S with a splint (one unit) and over it, a circular bandage (two units). Both configurations had the same weight. Five prototypes of each group were built and mechanically tested. Three-point flexural tensile strength and maximum deflection were measured and compared.
\end{abstract}

Results: The previously splinted prototypes (group S) obtained higher tensile strength with the same weight $(p<$ 0.05).

Discussion: No other study regarding strength and configuration of circular casts for distal radius fractures immobilization has been previously published, leading to a high variability in construction among orthopedic surgeons. Data confirms that applying a splint before circular bandage offers more mechanical resistance to the cast in flexion, with the same weight.

Conclusion: Applying a splint before circular bandage for plaster casts used for distal radius fractures make them more resistant to usual forces.

Keywords: Wrist fracture, Plaster of Paris, Plaster cast, Conservative treatment, Splint, Immobilization, Distal radius fracture

\section{Introduction}

Distal radius is the location for one-sixth of the whole body fractures. Ninety percent of them are extraarticular, known as Colles' fractures [1].

Conservative treatment, namely immobilization without surgery, is the most commonly applied treatment in this type of fractures. Several studies suggest that this

\footnotetext{
* Correspondence: adelgado@ujaen.es

${ }^{4}$ Department of Orthopaedic Surgery, Complejo Hospitalario de Jaén, Jaén, Spain

${ }^{5}$ Department of Surgery, University of Jaén, Jaén, Spain

Full list of author information is available at the end of the article
}

treatment achieves similar clinical results to surgery in patients older than 60 years [2-6], emphasizing the high number of patients treated conservatively in common practice.

Although some new materials have been developed [7-13], plaster cast remains the gold standard and the most frequently used form of immobilization [2, 14]. Plaster as a material is isotropic. Thus, it is able to resist forces in any direction with the same strength. Nevertheless, the plaster cast has a form (shape) that distributes the material in a special form to get more resistant in some directions, so it is anisotropic. 
There are different forms of applying the cast for this type of fractures [15-17], but there is no conclusive data to indicate that one method (long versus short plaster casts [15], double thickness against reinforced single thickness [16], single reinforcing ridges [17]) is superior to other. Our current practice is to apply a circumferential closed molded cast directly onto the arm (when reduction is not necessary). If reduction is necessary or inflammation is expected, we apply an open circumferential cast that is changed to a circumferential closed molded cast after inflammation has subsided (about 710 days later).

Usual practice is to maintain the cast for 5-6 weeks. Recent reports indicate that immobilization cannot be shortened without losing reduction [18]. So getting a strong construction of the cast is important, with the minimum weight possible, so the cast does not deteriorate with time.

Classical texts indicate two basic ways to apply a circumferential antebraquial cast [19]. Italian school, popularized by Morandi, consisted of applying circumferential plaster cast bandages directly over padding. German school, popularized by Böhler, apply very little (or no) padding, then a dorsal plaster splint, and over it, the rest of the circumferential plaster cast bandages [19]. Final result in terms of contention of fracture seems similar, but strength to usual forces in 6 weeks is unknown.

The aim of this work is to compare the resistance to usual forces (flexion) of two commonly used configurations of cylindrical plaster cast: one applying a splint before circumferential casting, and the other with circumferential casting alone, using the same quantity of plaster (same weight) in both configurations.

\section{Material and methods}

Using a specifically modified mannequin's forearm as a human model, ten plaster cast prototypes were made, based in two techniques of cylindrical plaster cast application for the treatment of distal radius fractures (five prototypes with each technique): Same quantity of material (Cast) was used for both techniques (Fig. 1). When the circumferential bandage was applied, it was applied uniformly, continuously, without reinforcement at any point.

a. Circumferential casting alone (C): A layer of standard padded bandage (Texban-s $\mathrm{s}^{\circ}$, Texpol, 100\% polyester, $10 \times 270 \mathrm{~cm}$ ) was applied. Over it, three plaster bandages (Guypse ${ }^{\oplus}$, BSN medical, $10 \times 270$ $\mathrm{cm}$ ) were applied circumferentially, on a regular way, molded on the mannequin's forearm. Each prototype was denominated with the letter $\mathrm{C}$ and a

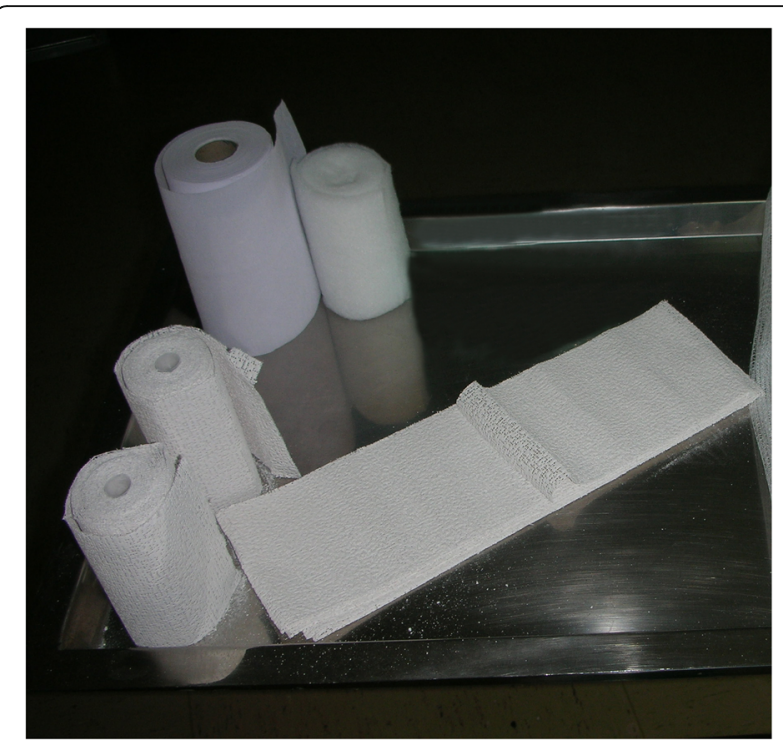

Fig. 1 Material used for the plaster cast preparation. A layer of standard padded bandage (Texban-5 $\varsigma^{\varpi}$, Texpol, 100\% polyester, $10 \times$ $270 \mathrm{~cm}$ ) and three plaster bandages (Guypse ${ }^{\oplus}$, BSN medical, $10 \times$ $270 \mathrm{~cm}$ ) (one of them has been flattened into a splint for group S). In both prototypes, the quantity of plaster of Paris (weight) is the same

number, according to the order in which they were included in our study (e.g., C1.) (Fig. 2a, b).

b. Circumferential casting with a splint (S): A layer of standard padded bandage was applied, similar to that applied to group C. Over it, one of the plaster bandages was applied as a dorsal splint, and then, the other two plaster bandages were placed on a circumferential way, molded on the splint, and then on the mannequin's forearm. Each prototype was denominated with the letter $\mathrm{S}$ and a number, according to the order in which they were included in our study (e.g., S1.) (Fig. 3a, b).

After 2 days (time necessary for the plaster to set completely), the mannequin's forearm was withdraw (mannequin was detachable in pieces as not to damage the cast). The prototypes underwent a three-point bending mechanical test in flexion. A single load was given midway between both ends of the prototype using an electromechanical press machine manufactured by SchenkTrebel (Fig. 4). Data obtained were tensile strength in Newtons and maximum deflection in millimeters before breakage.

Results were analyzed between groups using the free software "R-commander" ( $\mathrm{R}$ Development Core Team (2011) http://www.R-project.org/). Variables were described in general and specifically for each kind of plaster cast. These variables were mean, median, standard deviation, and range (minimum and maximum). 


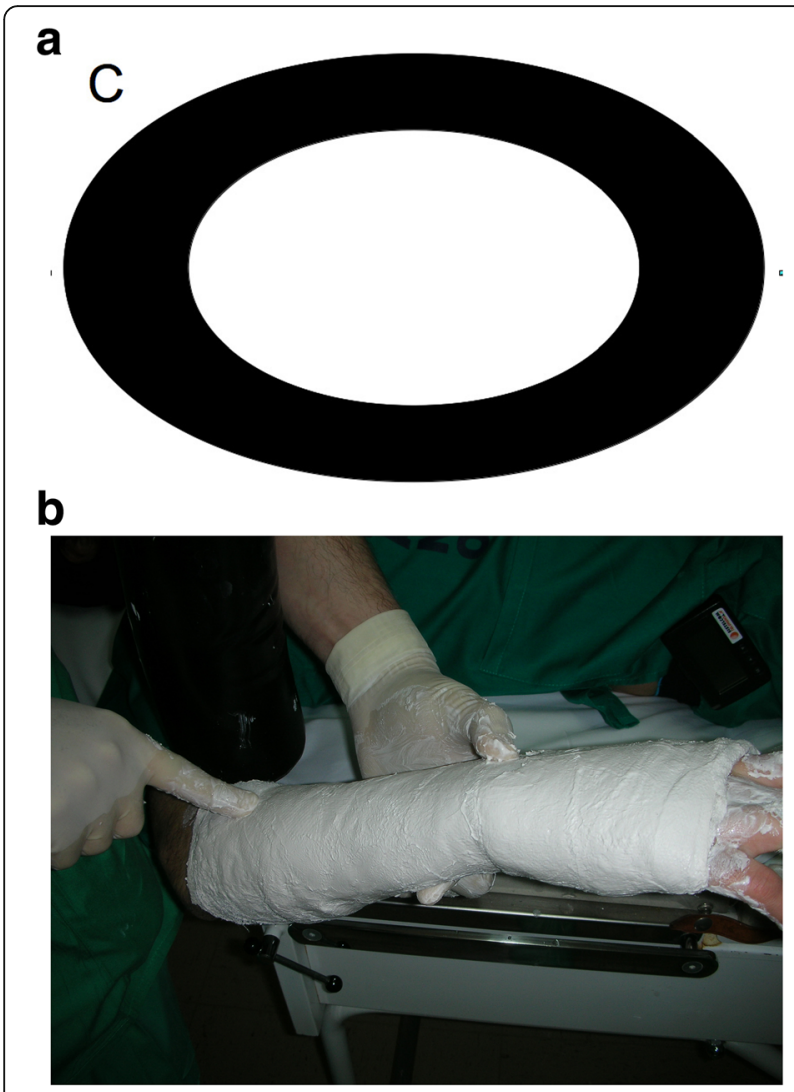

Fig. 2 Circular plaster alone. a Diagram of the system of applying the cast (transversal cut). b Application in clinical setting

Nonparametric tests (Mann-Whitney test for independent samples, with a degree of significance of $\alpha<0.05$ ) were applied for every variable in the contrast of hypothesis that was as follows:

- Null hypothesis (HO). The variable has no statistically significant differences according to the type of plaster cast.

- Alternative hypothesis (H1). The variable has statistically significant differences according to the type of plaster cast.

\section{Results}

Data obtained from mechanical tests are summarized in Table 1 and Fig. 5. The mean tensile strength in circumferential casting with a splint (S) group was higher than in circumferential casting alone $(C)$ group (nearly double, $2195 \mathrm{~N}$ versus 1273 $\mathrm{N})$, with a statistically significant difference $(p=$ $0.021)$. Mean maximum deflection $(p=0.009)$ was also superior for the circumferential casting with a splint group (S), with statistically significant differences (Table 1).

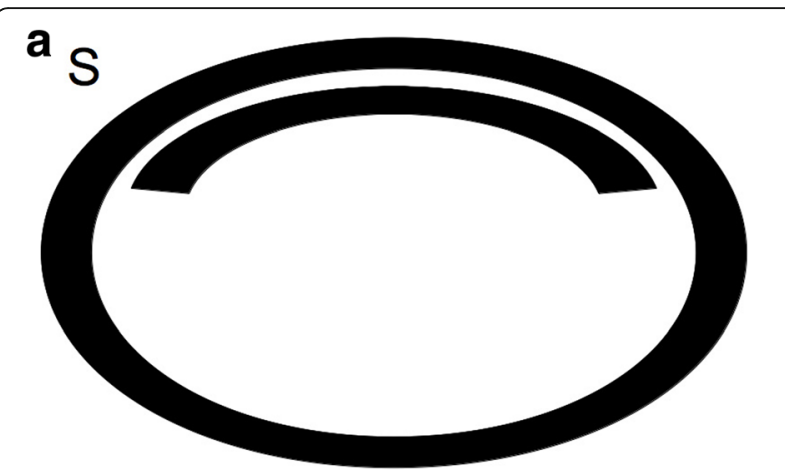

b

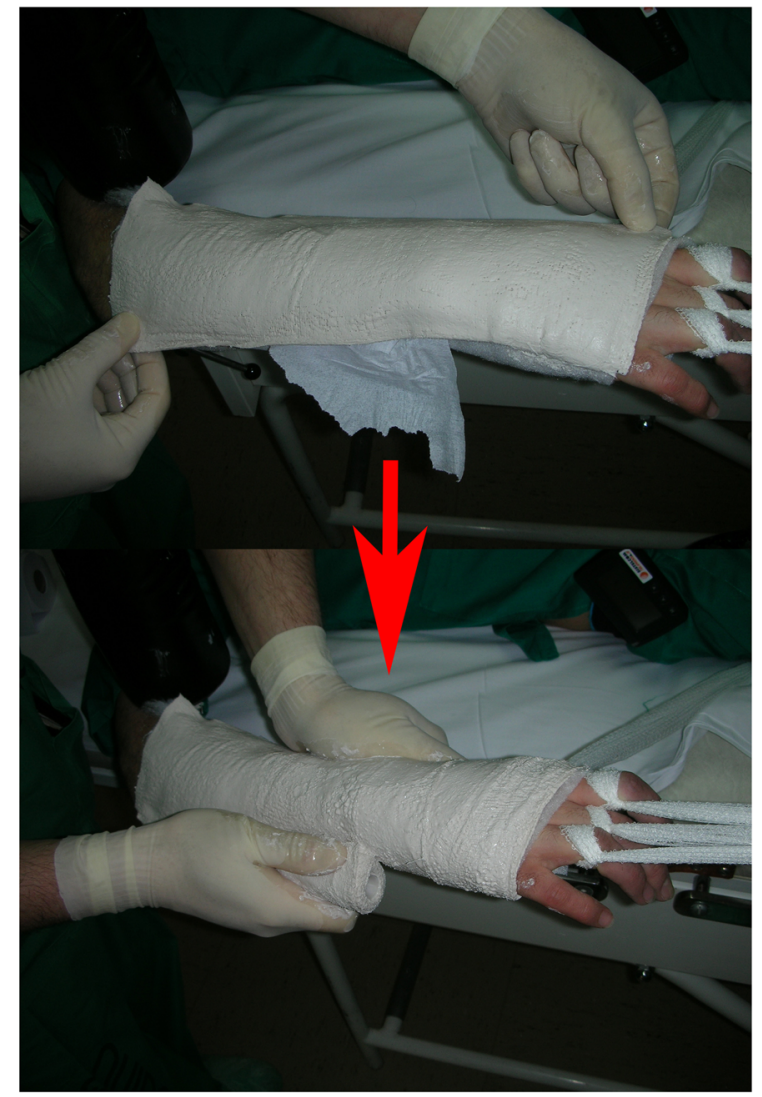

Fig. 3 Splint applied under the circular plaster cast (before it). a Diagram of the system of applying the cast (transversal cut). $\mathbf{b}$ Application in clinical setting

\section{Discussion}

The main finding in our study was that applying a splint before circumferential bandage makes the cast more resistant to bending loads, compared to a circumferential cast of the same weight (with the same quantity of material).

This fact allows us to get a more stable and resistant immobilization in conservative treatment of distal radius fractures, with the same quantity of plaster. Furthermore, the use of a splint (S group) allows a better adaptation to the anatomy of the forearm (authors' own 


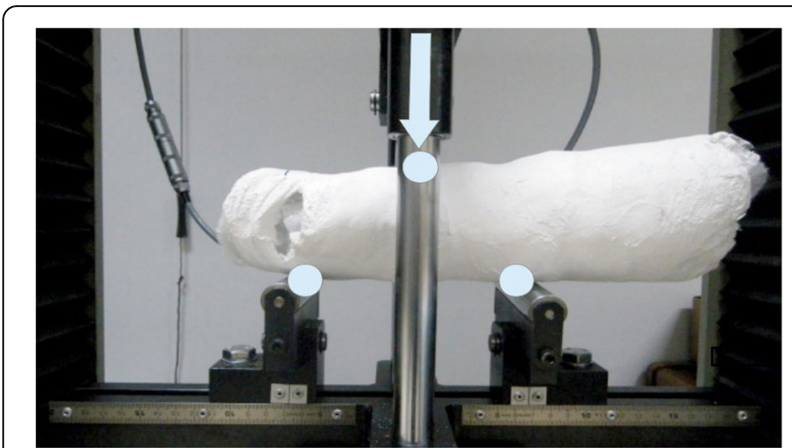

Fig. 4 Specimen installed on machine for testing. A load is applied in the central bar to get a three-point bending test, in a similar way as they are loaded in the patient. The circles show the equidistant deflection points (separated by $7 \mathrm{~cm}$ ) and the arrow shows the direction of the single load applied

opinion). Moreover, this addition does not imply either a technical difficulty or higher costs.

No other study comparing the strength of different circular plaster casts configurations for distal radius fracture immobilization has been found, but some studies have compared different configurations of splints to get more resistance to bending forces.

Stewart et al. [16] compared different configurations of splinting and found that mounting reinforcement ridges on the splint could augment $100 \%$ the bending strength of the plaster with only a $20 \%$ increase in weight. This article emphasizes the great change in bending strength that can be achieved with just small changes in configuration, as used in our study. In fact, applying a splint under a circular cast makes similar to adding ridges to a splint, increasing bending resistance, similar to the study of Stewart et al. [16]. Theopold et al. [17] obtained similar results in a study quite similar to that of Stewart et al. [16], applying reinforcements to splints. Ridges or reinforcements make the cast more bulky, being sometimes disappointing to the patient. For our study, just adding a splint before applying the circumferential cast make no difference to the external aspect of the plaster (Figs. 1 and 2), being well tolerated by the patient.

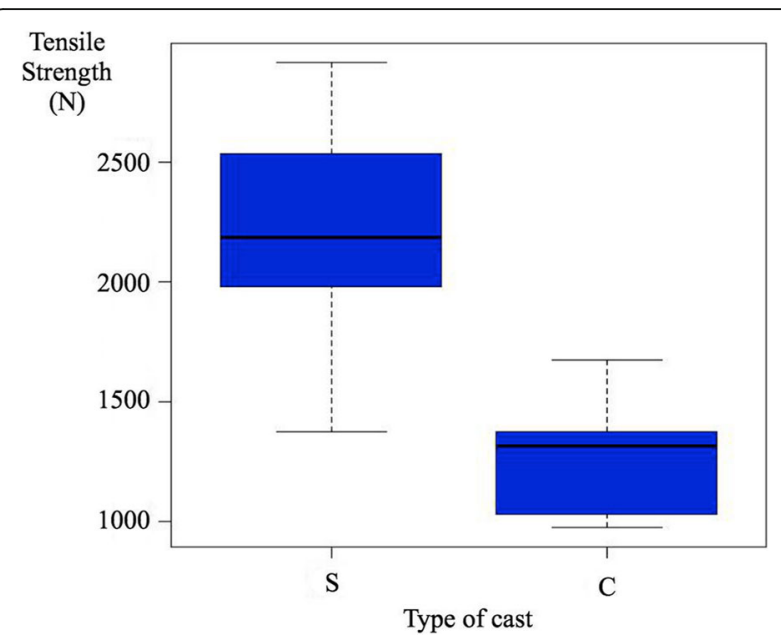

Fig. 5 Box plots showing the maximum load (tensile strength) before breaking in each group. $\mathrm{S}$ = circumferential casting with a splint group, and $\mathrm{C}=$ circumferential casting alone group. The area within the box includes values between the 25 percentile and the 75 percentile, while the black line represents the median. See that strength is superior in the circumferential casting with a splint group (S)

The short plaster cast or splint is the most commonly used form of immobilization of distal radius fractures nowadays. Some studies $[15,20]$ showed that short plaster casts provide at least similar results to the long ones. We have used for this study a model of short plaster cast. Nevertheless, we consider that the results of this article for the wrist are also applicable to long plaster casts, as mechanical forces were applied distally to the elbow.

The main forces that should resist the cast are at the wrist. In a practical setting, usual forces and breaking of plaster occur at the wrist, so this is the "weak point" of the cast [20-22]. Moreover, the volar side of the wrist is considered, in classical teaching [19], the "weak point" because this area is more prone to hits and rubs that can weaken it. This is the reason that we wondered about the best way to avoid this form of breaking without increasing the weight or thickness of the cast. Moreover, mechanical testing was performed in this way, in flexion, to get the information about the "weak point" of the

Table 1 Results of biomechanical testing and statistical analysis of biomechanical data

\begin{tabular}{llllllllll}
\hline & Prototype & $\boldsymbol{N}$ & Mean & Median & Standard deviation & Minimum & Maximum & $\boldsymbol{P}$ value & Result \\
\hline Tensile strength (N) & $\mathrm{S}$ & 5 & 2195.38 & 2182.20 & 581.81 & 1371.80 & 2913.70 & $\mathbf{0 . 0 2 1}$ & $\begin{array}{l}\text { Statistically significant } \\
\text { (S stronger) }\end{array}$ \\
& $\mathrm{C}$ & 5 & 1273.38 & 1315.00 & 282.72 & 974.40 & 1674.00 & \\
Maximum deflection $(\mathbf{m m})$ & Total & 10 & 1734.38 & 1522.90 & 649.70 & 974.40 & 2913.70 & \\
& $\mathrm{~S}$ & 5 & 32.27 & 33.30 & 4.16 & 25.74 & 37.20 & $\mathbf{0 . 0 1}$ & \\
& $\mathrm{C}$ & 5 & 14.18 & 14.04 & 5.76 & 6.21 & 21.44 & & \\
& Total & 10 & 23.22 & 23.59 & 10.65 & 6.21 & 37.20 & \\
\hline
\end{tabular}

$S$ circumferential casting with a splint group, $C$ circumferential casting alone group, $N$ number of prototypes tested 
plaster, resembling usual forces. Mechanical testing was not performed in other directions because it is not the common way of failure of these casts. One limitation of the study may be found in the small number of prototypes tested, but we do not feel this as a problem because, despite the short series studied, we found statistically significant differences between $\mathrm{S}$ and $\mathrm{C}$ groups, so we have conclusive results and we can draw strong conclusions. Another limitation is that this is a mechanical basic study, so further clinical research is required. Other forms of applying circumferential plaster could be possible, but they are not so commonly used in Europe as the prototypes here studied. Applying the splint to the volar side of the wrist is a possibility, but in the practical setting is somehow difficult to apply and we do not have any report of putting the plaster in that way. So we did not feel it useful to study other plaster configurations.

The application of the results of this article may be widespread. As known, distal radius fractures involve $16 \%$ of the whole body's fractures, and $90 \%$ of them are extraarticular [1]. As several authors refer [2-6], conservative treatment with plaster cast is the most used type of treatment in older patients, so the addition of a splint ( $\mathrm{S}$ group) to the circular cast may be widely used in the daily routine. Moreover, distal radius fractures are even more frequent in childhood (physeal injuries), and the conservative treatment is also the most commonly type of treatment used [20-22].

\section{Conclusion}

In conclusion, the application of a dorsal splint before the circular plaster cast for conservative treatment in distal radius fractures provide more strength to flexion forces than circular plaster cast performed with the same quantity of plaster. The strength is higher, with same weight and cost. We strongly recommend this form of application of plaster.

\section{Abbreviations \\ HO: Null hypothesis; $\mathrm{H1}$ : Alternative hypothesis}

\section{Acknowledgements}

None.

\section{Authors' contributions}

Espejo-Reina, Alejandro, MD: Conception of the work; acquisition, analysis, and interpretation of data; he drafted the work and substantively revised it. Carrascal-Morillo, María T, PhD: Design of the work; acquisition, analysis, and interpretation of data; she substantively revised the paper. Delgado-Martínez, Alberto $\mathrm{D}, \mathrm{MD}, \mathrm{PhD}$, FEBOT: Conception and design of the work; analysis and interpretation of data; he has drafted the work and revised it (final revision). The authors read and approved the final manuscript.

\section{Authors' information}

None.

\section{Funding}

None.

\section{Availability of data and materials}

The datasets used and/or analyzed during the current study are available from the corresponding author on reasonable request.

Ethics approval and consent to participate

Not applicable.

\section{Consent for publication}

Not applicable.

\section{Competing interests}

The authors declare that they have no competing interests.

\section{Author details}

'Deparment of Orthopaedic Surgery, Clínica Espejo, Paseo Reding, Málaga, Spain. ${ }^{2}$ Deparment of Orthopaedic Surgery, Hospital Vithas Parque San Antonio, Málaga, Spain. ${ }^{3} H i g h e r$ Technical School of Industrial Engineering, Madrid, Spain. ${ }^{4}$ Department of Orthopaedic Surgery, Complejo Hospitalario de Jaén, Jaén, Spain. ${ }^{5}$ Department of Surgery, University of Jaén, Jaén, Spain.

Received: 11 December 2019 Accepted: 20 January 2021

Published online: 30 January 2021

\section{References}

1. Utrillas-Compaired A, Delgado-Martinez AD, Delgado-Serrano P. Fracturas de la extremidad distal del cúbito y del radio. In: Delgado-Martínez AD, editor. Cirugia Ortopédica y Traumatologia. 4th ed. Madrid: Editorial Médica Panamericana; 2018. p. 451-8.

2. Handoll HH, Huntley JS, Madhok R. External fixation versus conservative treatment for distal radial fractures in adults. Cochrane Database Syst Rev. 2007;18(3):CD006194.

3. Aktekin CN, Altay M, Gursoy Z, Aktekin LA, Ozturk AM, Tabak AY. Comparison between external fixation and cast treatment in the management of distal radius fractures in patients aged 65 years and older. $J$ Hand Surg. 2010;35(5):736-42.

4. Arora R, Lutz M, Deml C, Krappinger D, Haug L, Gabl M. A prospective randomized trial comparing nonoperative treatment with volar locking plate fixation for displaced and unstable distal radial fractures in patients sixty-five years of age and older. J Bone Joint Surg [Am]. 2011;93(23):214653.

5. Wong TC, Chiu Y, Tsang WL, Leung WY, Yam SK, Yeung SH. Casting versus percutaneous pinning for extra-articular fractures of the distal radius in an elderly Chinese population: a prospective randomised controlled trial. J Hand Surg Eur. 2010;35(3):202-8.

6. Azzopardi T, Ehrendorfer S, Coulton T, Abela M. Unstable extra-articular fractures of the distal radius: a prospective, randomised study of immobilisation in a cast versus supplementary percutaneous pinning. J Bone Joint Surg [Br]. 2005;87(6):837-40.

7. Colditz JC. Plaster of Paris: the forgotten hand splinting material. J Hand Ther. 2002;15(2):144-57.

8. Deshpande SV. An experimental study of pressure-volume dynamics of casting materials. Injury. 2005;36(9):1067-74.

9. Zmurko MG, Belkoff SM, Herzenberg JE. Mechanical evaluation of a soft cast material. Orthopedics. 1997;20(8):693-8.

10. Bowker P, Powell ES. A clinical evaluation of plaster-of-Paris and eight synthetic fracture splinting materials. Injury. 1992;23(1):13-20.

11. Philbin TM, Gittins ME. Hybrid casts: a comparison of different casting materials. J AM Osteopath Assoc. 1999;99(6):311-2

12. Charles MN, Yen D. Properties of a hybrid plaster-fibreglass cast. Can J Surg. 2000;43(5):365-7.

13. Berman AT, Parks BG. A comparison of the mechanical properties of fiberglass cast materials and their clinical relevance. J Orthop Trauma. 1990; 4(1):85-92.

14. Blakeney WG. Stabilization and treatment of Colles' fractures in elderly patients. Clin Interv Aging. 2010;18(5):337-44.

15. Webb GR, Galpin RD, Armstrong DG. Comparison of short and long arm plaster casts for displaced fractures in the distal third of the forearm in children. J Bone Joint Surg. 2006;88(1):9-17.

16. Stewart T, Cheong W, Barr V, Tang D. Strong and light plaster casts? Injury. 2009;40(8):890-3. 
17. Theopold C, Bush JA, Wilson SW, Bayat A. Optimal plaster conformation derived using a custom-made jig to obtain maximum strength of protective plaster of Paris for hand surgery. J Trauma. 2007;63(5):1074-8.

18. Christersson A, Larsson S, Östlund B, Sandén B. Radiographic results after plaster cast fixation for 10 days versus 1 month in reduced distal radius fractures: a prospective randomised study. J Orthop Surg Res. 2016;11 (1):145.

19. Sanchis Olmos V, Vaquero-gonzález F. La técnica de los vendajes enyesados. Barcelona: Ed científico-medica; 1957.

20. Marcheix PS, Peyrou P, Longis B, Moulies D, Fourcade L. Dorsal distal radius fractures in children: role of plaster in redisplacement of these fractures. J Pediatr Orthop B. 2011;20(6):372-5.

21. Alemdaroglu KB, Itar S, Cimen O, Uysal M, Alagoz E, Atlihan D. Risk factors in redisplacement of distal radial fractures in children. J Bone Joint Surg. 2008;90(6):1224-30.

22. Alemdaroglu KB, Iltar S, Aydogan NH, Say F, Kilinc CY, Tiftikc U. Three-point index in predicting redisplacement of extra-articular distal radial fractures in adults. Injury. 2010;41(2):197-203.

\section{Publisher's Note}

Springer Nature remains neutral with regard to jurisdictional claims in published maps and institutional affiliations.

Ready to submit your research? Choose BMC and benefit from:

- fast, convenient online submission

- thorough peer review by experienced researchers in your field

- rapid publication on acceptance

- support for research data, including large and complex data types

- gold Open Access which fosters wider collaboration and increased citations

- maximum visibility for your research: over $100 \mathrm{M}$ website views per year

At $\mathrm{BMC}$, research is always in progress.

Learn more biomedcentral.com/submissions 